\title{
Sistem Automatic Text Summarization Menggunakan Algoritma Textrank
}

\author{
Muhammad Adib zamzam, Cahyo Crysdian, Khadijah Fahmi Hayati Holle
}

\begin{abstract}
Abstrak-Text summarization (perangkuman teks) adalah pendekatan yang bisa digunakan untuk meringkas atau memadatkan teks artikel yang panjang menjadi lebih pendek dan ringkas sehingga hasil rangkuman teks yang relatif lebih pendek bisa mewakilkan teks yang panjang. Automatic Text Summarization adalah perangkuman teks yang dilakukan secara otomatis oleh komputer. Terdapat dua macam algoritma Automatic Text Summarization yaitu Extraction-based summarization dan Abstractive summarization. Algoritma TextRank merupakan algoritma extraction-based atau extractive, dimana ekstraksi di sini berarti memilih unit teks (kalimat, segmen-segmen kalimat, paragraf atau passages), lalu dianggap berisi informasi penting dari dokumen dan menyusun unit-unit (kalimat-kalimat) tersebut dengan cara yang benar. Hasil penelitian dengan input 50 artikel dan hasil rangkuman sebanyak $12,5 \%$ dari teks asli menunjukkan bahwa sistem memiliki nilai recall ROUGE 41,659 \%. Nilai tertinggi recall ROUGE tertinggi tercatat pada artikel 48 dengan nilai 0,764. Nilai terendah recall ROUGE tercatat pada artikel 37 dengan nilai 0,167 .
\end{abstract}

Kata Kunci-Graf; Otomatis; Rangkuman; Rangkuman Otomatis; Teks;

Abstract - Text summarization is an approach to summarize or condense long text to shorter text, so that the shorter text is represent the real text. Automatic Text Summarization is text summarization which done automatically by computer. There are two methods, first Extraction-based summarization and Abstractive summarization. TextRank Algorithm is extraction-based or extractive, in the current context, extraction means choosing the text unit (sentences, sentence segments, paragraph or passages), then it is calculated and considered as important and finally the units is arranged at the correct manner. The result from $\mathbf{5 0}$ articles with summary rate of $12,5 \%$ had the ROUGE recall value $41.659 \%$. Highest value known at 48th article with value 0,764 . Lowest ROUGE recall value known at 37th with value 0,167.

Keywords-Automatic Summarization; Graph; Summarization; Text; TextRank;

\section{Pendahuluan}

$\mathrm{P}$ ertumbuhan internet yang sangat cepat berbanding lurus dengan jumlah informasi dan dokumen online

Muhammad Adib zamzam is with the Informatic Engineering Departement of UIN Maulana Malik Ibrahim, Malang, Indonesia (email15650058@student.uin-malang.ac.id)

Cahyo Crysdian, is with the Informatic Engineering Departement of UIN Maulana Malik Ibrahim, Malang, Indonesia.

Khadijah Fahmi Hayati Holle is with the Informatic Engineering Departement of UIN Maulana Malik Ibrahim, Malang, Indonesia yang sangat besar pula. Di masa ini, media yang paling banyak digunakan untuk menyampaikan informasi adalah media teks [4]. Sehingga menemukan sebuah representasi yang tepat dari informasi tekstual (rangkuman) merupakan sebuah hal yang penting untuk membantu pemahaman keseluruhan teks supaya lebih cepat.

Rangkuman penting untuk telaah sekilas dari keseluruhan bagian dokumen atau bab. Penulisan rangkuman pada umumnya bisa dilakukan dengan mudah jika pembaca relatif familiar terhadap teks yang dibaca atau jika teks tersebut tidak terlalu panjang. Hasil rangkuman setiap individu pun berbeda karena apa yang ditulis juga merupakan buah pikiran individu yang bersifat subjektif sedangkan untuk menghasilkan rangkuman yang baik dan bagus perlu pertimbangan yang bersifat objektif.

Salah satu pembahasan pada Natural Language Processing adalah Text Summarization. Text Summarization bertujuan untuk mengkaji tentang otomasi perangkuman teks dengan pilihan metode-metode / algoritma yang bermacam-macam. Automatic text summarization, sebuah reduksi teks menjadi pada isi pentingnya ialah problem yang sangat kompleks yang dalam perkembangannya sejauh ini memberikan banyak tantangan pada komunitas ilmiah [15].

Dalam kesempatan ini peneliti hendak membangun sistem Automatic text summarization. Salah satu algoritma dalam pembahasan text summarization adalah Algoritma Textrank yang termasuk dalam kategori extractive summarization. Algoritma TextRank merupakan metode yang sederhana karena perangkuman dilakukan dengan menilai setiap kalimat dan melakukan perangkingan tanpa mengubah isi teks asli yang dijadikan rangkuman.

\section{LANDASAN TEORI}

Text summarization (perangkuman teks) adalah pendekatan yang bisa digunakan untuk meringkas atau memadatkan teks artikel yang panjang menjadi lebih pendek dan ringkas sehingga hasil rangkuman teks yang relatif lebih pendek bisa mewakilkan teks yang Panjang [16]. Pada dasarnya menggunakan prinsip Natural Language Processing dan algoritma-algoritma untuk membuat sistem mengerti artikel-artikel dan menghasilkan rangkuman yang lebih pendek dan 
efisien. Automatic summarization (otomasi perangkuman) adalah proses mengurangi dokumen teks menggunakan program komputer dalam rangka membuat rangkuman yang menyimpan titik-titik terpenting dari dokumen asli. Automatic data summarization adalah wilayah yang sangat penting dalam machine learning dan data mining. Di zaman ini, teknologi summarization digunakan pada banyak sektor industri. Sebuah contoh adalah search engine seperti Google. Contoh lain yang termasuk yaitu document summarization, image collection summarization dan video summarization. pokok summarization adalah menemukan bagian yang representatif, yang memiliki informasi dari seluruh bagian. Macam-macam summarization dijelaskan pada bagian berikut ini.

\section{A. Extraction-based summarization}

Ekstraksi berarti memilih unit teks (kalimat, segmen-segmen kalimat, paragraf atau passages), lalu dianggap berisi informasi penting dari dokumen dan menyusun unit-unit ini dengan cara yang benar. Menurut Radev et al., algoritma-algoritma berbasis ekstraksi terbagi menjadi tiga, yaitu:

\section{Surface-level}

Metode sentence scoring mengambil 8 nilai dari sebuah kalimat diantaranya adalah TF/IDF, huruf besar, kata benda, frasa isyarat, data numerik, panjang kalimat, posisi kalimat dan kesamaan dengan judul yang kemudian nilainya diproses sehingga menjadi skor dari sebuah kalimat. Skor tersebut menjadi hasil data latih dimana data tersebut digunakan sebagai acuan decision tree untuk menentukan sebuah kalimat termasuk dalam rangkuman atau tidak. Score sentence termasuk metode supervised [14].

2. Intermediate-level

Barzilay (1997) melakukan penelitian perangkuman ekstraktif dengan menggunakan lexical chain. Barzilay menyatakan bahwa ekstraksi rangkuman dapat dilakukan dengan menggunakan lexical chain sebagai model topik pembahasan [1].

\section{Deep parsing}

Chengcheng (2010) menggunakan metode summarization yang berdasarkan Rhetorical Structure Theory (RST). RST merupakan sebuah kerangka kerja yang dirancang untuk perhitungan struktur teks pada tingkat klausa. Sistem mengutip (extract) struktur retorikal dari teks dan menggabungkan relasi retorikal antara kalimat-kalimat dan memotong bagian yang kurang penting [3].

\section{B. Abstractive summarization}

Teknik ekstraksi hanya menyalin informasi yang dianggap paling penting oleh sistem (key clause, kalimat atau paragraf-paragraf), teknik abstraksi melibatkan paraphrasing section dari dokumen asal. Pada umumnya, abstraksi dapat membentuk teks lebih kuat daripada ekstraksi, namun program yang mampu melakukannya lebih sulit untuk dikembangkan mengetahui syarat sistem tersebut harus menggunakan teknologi natural language generation, dimana teknologi tersebut masih merupakan bidang yang berkembang.

Hasil rangkuman dari metode-metode tersebut kemudian dapat dievaluasi dengan menggunakan metode-metode untuk evaluasi rangkuman yang bisa dibagi menjadi dua kategori, yaitu intrinsik dan ekstrinsik. Evaluasi Intrinsik mengukur kualitas rangkuman secara langsung (membandingkannya dengan rangkuman yang ideal). Metode ekstrinsik mengukur seberapa baik rangkuman membantu kinerja tugas tertentu (klasifikasi dan semacamnya) [10].

C. Algoritma TextRank

TextRank merupakan metode pemeringkatan berdasarkan graf (graph-based ranking) dimana graf merupakan hasil ekstraksi dari teks menggunakan natural language text. Graf pada TextRank yaitu graf berbobot tak berarah. Algoritma graph-based ranking merupakan sebuah cara menentukan simpul-simpul penting pada graf, berdasarkan pada informasi global yang digambarkan secara rekursif dari keseluruhan graf. Ide pokoknya yaitu menerapkan voting atau rekomendasi dari simpul-simpul di graf. Ketika satu simpul a terhubung ke simpul b, maka sejatinya simpul a memberi suara (vote) pada simpul b tersebut. Semakin tinggi angka penilaian pada sebuah simpul, semakin penting pula simpul tersebut. Sehingga, skor yang berhubungan dengan sebuah simpul ditentukan berdasarkan suara yang diperoleh simpul dari simpul-simpul lain dan skor simpul-simpul yang memperoleh suara [11].

Misal, $\mathrm{G}=(\mathrm{V}, \mathrm{E})$ sebagai graf dengan $\mathrm{V}$ adalah sekumpulan simpul dan $\mathrm{E}$ adalah sekumpulan sisi, dimana E merupakan sebagian dari VxV. Sebuah sisi memiliki bobot yang dapat ditentukan nilainya dengan rumus kesamaan (similar formula). Pada simpul Vi, terdapat In (Vi), simpul-simpul yang menunjuk ke simpul tersebut (predecessor) dan Out (Vi), sekumpulan simpul-simpul yang ditunjuk oleh Vi (successor). Skor total pada simpul Vi didefinisikan seperti berikut [2]:

$$
S\left(V_{i}\right)=(1-d)+d * \sum_{j \in \operatorname{In}\left(V_{i}\right)} \frac{1}{\left|O u t\left(V_{j}\right)\right|} S\left(V_{j}\right)
$$

dimana d adalah damping factor yang dapat bernilai diantara $0-1$. Nilai d berperan dalam mengintegrasikan probabilitas perpindahan dari satu simpul ke satu simpul acak pada graf. Pada konteks web surfing, algoritma ini menerapkan "random surfer model", dimana pengguna secara acak menekan link dengan kemungkinan d dan berpindah ke halaman yang sama sekali baru dengan kemungkinan 1-d. Faktor d biasanya bernilai 0,85 [2].

Setiap iterasi diperoleh nilai simpul baru. Error diketahui dengan mengurangi hasil iterasi sekarang dengan hasil iterasi sebelumnya dengan rumus berikut:

$$
S^{k+1}\left(V_{i}\right)-S^{k}\left(V_{i}\right) \text {. }
$$

Setelah menjalankan algoritma, skor dihubungkan pada tiap simpul, yang mewakili "pentingnya" simpul dalam suatu graf. Nilai akhir yang diperoleh setelah TextRank selesai tidak dipengaruhi oleh pilihan nilai awal melainkan jumlah iterasi menuju ambang bataslah yang berpengaruh.

Metode yang diterapkan merupakan graf berbobot maka perlu diketahui bobot tiap sisi yang 
menghubungkan simpul-simpul. Maka rumus TextRank adalah sebagai berikut:

$$
W S\left(V_{i}\right)=(1-d)+d * \sum_{V_{j} \in \operatorname{In}\left(V_{i}\right)} \frac{w_{j i}}{\sum_{V_{k} \in O u t\left(V_{j}\right)} w_{j k}} W S\left(Y_{j}\right)
$$

Rincian Rumus:

$\mathrm{WS}(\mathrm{Vi})=$ Bobot simpul Vi \& d = damping factor $(0.85)$

$\mathrm{Vk}=$ Himpunan simpul tetangga $\mathrm{Vj}$

$\mathrm{WS}(\mathrm{Vi})=$ Bobot simpul $\mathrm{Vj}$

$\mathrm{Vj}$ = Himpunan simpul tetangga $\mathrm{Vi}$

wji \& wjk = bobot sisi antara simpul j\&i dan j\&k secara berurutan

Automatic document summarization adalah proses reduksi dokumen yang menetapkan bagian teks yang penting. Pada penelitiannya dilakukan uji coba 4 algoritma similarity yang berbeda untuk efisiensi algoritma TextRank dalam menghasilkan rangkuman [6].

Nanos (2017) membahas perangkuman otomatis pada dokumen transkrip pertemuan (meeting) pada virtual meeting systems. Representasi struktur TextRank biasanya hanya menggunakan graf saja, namun pada penelitian ini ditambahkan struktur pertemuan. Hal ini membantu ekstraksi kalimat yang paling penting dari sebuah transkrip pertemuan. Hasil menunjukkan bahwa memanfaatkan struktur tersebut dapat mengarahkan pada otomasi perangkuman yang lebih relevan [12].

\section{METODE PENELITIAN}

A. Data

Sumber yang digunakan untuk penelitian ini didapatkan dari situs tirto.id. Dokumen / artikel diambil sebanyak 50 teks berita atau eksposisi dari situs tersebut. Rangkuman manual (Rangkuman referensi atau ground truth) didapatkan dari 10 orang relawan. Satu artikel dirangkum oleh 10 orang. Hasil akhir sebuah rangkuman referensi dari sebuah artikel adalah himpunan kalimat-kalimat yang sering muncul dari 10 rangkuman referensi dari 1 artikel yang telah dibuat. Pengambilan data responden menggunakan Google form.

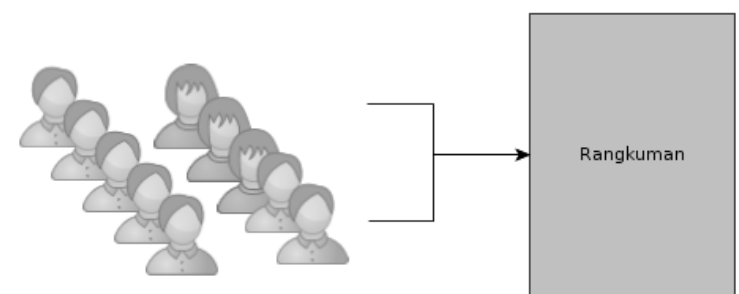

Gambar 1. Ilustrasi pengumpulan data 1 artikel dan pembuatan rangkuman referensi

\section{B. Desain dan Implementasi}

Desain dan implementasi sistem automatic text summarization setiap bagian dibahas pada bagian berikut. Sistem automatic text summarization pada kesempatan ini terdiri dari preprocess, main process, pengujian sistem dan rancangan user interface. Tahap preprocess adalah tahap mengolah isi artikel asli menjadi data yang siap dioleh pada main process. Tahap Main Process adalah tahap proses memperoleh nilai.

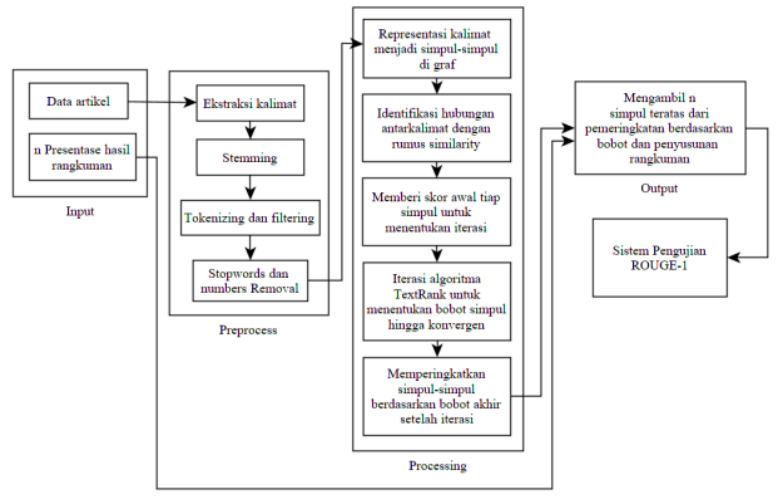

Gambar 2. Desain Sistem

i. Tahap Preprocess

a. Stemming

Stemming merupakan proses mengubah kata-kata yang memiliki imbuhan menjadi kata baku sehingga kata-kata yang diproses sistem adalah kata-kata dasar dalam Bahasa Indonesia. Stemming di kesempatan ini menggunakan modul Sastrawi yang tersedia di python.

\section{b. Tokenizing dan Filtering}

Tokenizing dan Filtering menghilangkan tanda baca yang tidak diperlukan dan dilakukan dengan memisahkan kalimat menjadi kata-kata [7]. Kalimat dipisah menjadi kata-kata dengan pemisah karakter spasi. Setiap kata-kata di kalimat kemudian dibandingkan apakah tidak termasuk pada kumpulan tanda baca. Jika tidak termasuk pada kumpulan tanda baca, maka kata-kata masuk dalam hasil preprocess, Tanda baca diambil dari modul standar library python string punctuation. Berikutnya mengubah semua token ke bentuk huruf kecil (lower case).

c. Stopwords and numbers Removal

Stopwords removal merupakan proses penghilangan kata tidak penting pada deskripsi melalui pengecekan kata-kata hasil parsing deskripsi apakah termasuk di dalam daftar kata tidak penting (stoplist) atau tidak [13]. Angka dalam bentuk kata tidak dimasukkan dalam perhitungan karena dapat menimbulkan multitafsir. Kamus stopword bahasa indonesia diperoleh dari modul python bernama stop_words.

\section{ii. Tahap Main Process}

Tahap Main Process adalah representasi teks menjadi graf, mengidentifikasi hubungan antarkalimat, pembobotan tiap kalimat berdasarkan identifikasi hubungan antarkalimat dan perangkingan kalimat berdasarkan bobot yang telah dihitung. Representasi dilakukan sebagai berikut:

1. Ektraksi kalimat dengan menjadikan seluruh kalimat sebagai simpul dalam graf. Graf yang dibuat adalah graf tak-berarah (undirected graph).

2. Identifikasi hubungan antarkalimat dengan membuat sisi antara simpul-simpul dengan menggunakan. cosine similarity. Cosine similarity merupakan fungsi yang menerima dua buah objek atau lebih dan mengembalikan nilai kemiripan (similarity) antara kedua objek tersebut berupa bilangan riil. Cosine 
Similarity mengukur dua objek vektor yang masing-masing memiliki n dimensi dengan menemukan nilai kosinus dari sudut yang dibentuk dua vektor tersebut. Umumnya, nilai yang dihasilkan oleh fungsi similarity berkisar pada interval [0...1] [17].

3. Memberi skor awal simpul berupa nilai acak untuk menentukan iterasi.

4. Melakukan iterasi algoritma TextRank sampai error rate tiap simpul konvergen atau mencapai ambang batas di bawah threshold. Error Rate disini adalah perbedaan antar dua skor simpul yang dihitung pada iterasi yang berurutan dengan rumus $\mathrm{x}$.

5. Kemudian simpul diurutkan berdasarkan skor akhirnya. Lalu diambil kalimat-kalimat dari ranking teratas sebanyak $50 \%$ sebagai hasil ekstraksi ringkasannya [5]. Proses ini diulangi hingga tiga kali hingga $12,5 \%$.

iii. Uji coba sistem

ROUGE (Recall-Oriented Understudy For Gisting Evaluation) adalah salah satu metode pengukuran otomatis; rangkuman dari hasil otomasi dibandingkan dengan rangkuman yang dibuat oleh manusia [8]. Pengukuran dilakukan dengan menghitung unit-unit yang cocok seperti n-gram (n-kata), urutan kata dan pasangan kata antara angkuman dari hasil otomasi dibandingkan dengan rangkuman yang dibuat oleh manusia. Berikut adalah rumus ROUGE - N.

ROUGE $-N=\frac{\left(\sum_{S \in\{\text { ReferenceSummaries }\}} \sum_{\text {gram }_{n} \in S} \operatorname{Count}_{\text {match }}\left(\text { gram }_{n}\right)\right)}{\left(\sum_{S \in\{\text { ReferenceSummaries }\}} \sum_{\text {gram }_{n} \in S} \operatorname{Count}\left(\text { gram }_{n}\right)\right)}$

ROUGE-N merupakan pengukuran yang berorientasi pada nilai recall, karena penyebut dari persamaan tersebut merupakan jumlah dari n-gram yang ada pada rangkuman manual (rangkuman referensi). Sehingga, recall di sini adalah nilai perbandingan $n$-gram hasil rangkuman sistem dengan $\mathrm{n}$-gram hasil rangkuman referensi.

\section{HASIL DAN PEMBAHASAN}

Bagian ini terdiri dari skenario uji coba, hasil uji coba dan pembahasan serta integrasi penelitian dengan pandangan Islam. Uji coba dilakukan untuk memperoleh nilai relevansi hasil rangkuman dari sistem yang telah dibangun berupa nilai recall.

A. Skenario Uji Coba

Skenario uji coba dimulai dengan pengumpulan data teks serta pembuatan rangkuman referensi. Pengumpulan dokumen / artikel sebanyak 50 teks berita dari situs tirto.id tidak dibatasi pada sebuah topik tertentu. Artikel-artikel kemudian dikumpulkan dan disimpan di sistem melalui menu input artikel. Setelah artikel dikumpulkan mulai membuat form online untuk mengumpulkan data rangkuman referensi dari 10 responden tetap. Responden tersebut akan memilih kalimat terbaik menurut responden yang berjumlah setengah dari jumlah kalimat keseluruhan dari sebuah artikel. Misal, sebuah artikel berjumlah 60 kalimat, maka responden memilih 30 kalimat terbaik menurutnya untuk dijadikan rangkuman referensi. Setiap individu responden bisa memilih kalimat yang berbeda-beda, sehingga dilakukan perhitungan kalimat mana yang dipilih paling banyak oleh responden-responden tersebut. Kalimat-kalimat tersebut kemudian dirangking menurut banyaknya pilihan dan diambil seperdelapan dari seluruh jumlah kalimat di artikel asli dan dikumpulkan menjadi satu rangkuman referensi.

Preprocessing (Stemming, Tokenizing, Filtering, dan Stopwords dan numbers Removal) dilakukan di dalam sistem, sehingga hasil prerpocess tidak disimpan. Setelah preprocessing, sistem melakukan penghitungan kalimat-kalimat mana saja yang menjadi kalimat terbaik untuk menjadi rangkuman. Kalimat terbaik ditunjukkan oleh hasil perhitungan skor TextRank hingga iterasi terakhir. Pengurutan kalimat dimulai dari yang memiliki skor TextRank tertinggi (descending). Kemudian rangkuman diambil seperdelapan dari keseluruhan kumpulan kalimat yang telah diurutkan secara descending, lalu disimpan di database.

Langkah terakhir yaitu melakukan evaluasi hasil rangkuman sistem yang dibandingkan dengan rangkuman referensi. Tingkat keberhasilan diukur dengan menggunakan nilai Recall dari nilai ROUGE-N (pada kesempatan ini menggunakan $\mathrm{N}=1 \sim$ ROUGE-1). Sistem penghitungan ini menggunakan library python Rouge. Hasil perhitungan kemudian juga disimpan di database.

\section{B. Hasil Uji Coba}

Bagian ini terdiri dari hasil pengumpulan dokumen, hasil pengolahan rangkuman referensi dan hasil pengujian rangkuman sistem. Berikut ini adalah contoh penjelasan salah satu artikel. Artikel tidak ditampilkan secara keseluruhan untuk mempercepat pembahasan.

Tabel 1. Isi artikel asli (data input) https://tirto.id/bangkitnya-penyakit-ganas-di-dunia-pasca-antibiotik-c9UK

\section{Bangkitnya Penyakit Ganas di Dunia Pasca-Antibiotik}

Bakteri semakin kebal antibiotik. Penyakit seperti pneumonia, TBC, sepsis, dan gonorea kian sulit disembuhkan karena antibiotik semakin tak efektif.

tirto.id - Pada 12-18 November 2018 diselenggarakan Pekan Kewaspadaan Antibiotik Dunia (World Antibiotic Awareness Week). Momentum ini bertujuan untuk meningkatkan kesadaran global terhadap resistensi antibiotik dan mendorong praktik terbaik di kalangan masyarakat umum, tenaga kesehatan, dan pembuat kebijakan untuk menghindari resistensi antibiotik yang telah mewabah.

$$
\cdots
$$

Momentum Pekan Kewaspadaan Antibiotik Dunia (World Antibiotic Awareness Week) 2018 mengingatkan kita untuk berpikir ulang dan mencari saran (Think twice. Seek advice), sebelum menggunakan antibiotik. Kita juga disadarkan bahwa penyalahgunaan antibiotik akan membuat kita semua berisiko.

Waktu kita dengan antibiotik hampir habis, sehingga menjadi tugas kita bersama untuk menjaga antibiotik. Sudahkah kita sadar? 
Artikel asli tersebut kemudian dipisah menjadi per kalimat untuk dijadikan pilihan kalimat yang bisa dipilih oleh responden. Kemudian mengambil data kalimat mana yang paling banyak dipilih oleh 10 responden.

Tabel 2. Pemisahan artikel menjadi kalimat-kalimat

\begin{tabular}{|c|c|}
\hline No. kalimat & Kalimat \\
\hline 1 & Bakteri semakin kebal antibiotik. \\
\hline 2 & $\begin{array}{l}\text { Penyakit seperti pneumonia, TBC, } \\
\text { sepsis, dan gonorea kian sulit } \\
\text { disembuhkan karena antibiotik } \\
\text { semakin tak efektif. } \\
\text { tirto.id - Pada 12-18 November } 2018 \\
\text { diselenggarakan Pekan }\end{array}$ \\
\hline 3 & $\begin{array}{l}\text { Kewaspadaan Antibiotik Dunia } \\
\text { (World Antibiotic Awareness } \\
\text { Week). }\end{array}$ \\
\hline 4 & $\begin{array}{l}\text { Momentum ini bertujuan untuk } \\
\text { meningkatkan kesadaran global } \\
\text { terhadap resistensi antibiotik dan } \\
\text { mendorong praktik terbaik di } \\
\text { kalangan masyarakat umum, tenaga } \\
\text { kesehatan, dan pembuat kebijakan } \\
\text { untuk menghindari resistensi } \\
\text { antibiotik yang telah mewabah. }\end{array}$ \\
\hline$\cdots$ & $\cdots$ \\
\hline$\ldots$ & $\ldots$ \\
\hline
\end{tabular}

Tabel 3. Data responden dan total jumlah kalimat.

\begin{tabular}{cccccccccccc}
\hline \hline \multicolumn{10}{c}{ No. } & \multicolumn{10}{c}{ Responden dan pilihan kalimat } \\
& 1 & 2 & 3 & 4 & 5 & 6 & 7 & 8 & 9 & 10 & Total \\
\hline \hline 1 & 1 & 1 & 1 & 1 & 1 & 0 & 1 & 1 & 1 & 1 & 9 \\
2 & 1 & 1 & 1 & 1 & 1 & 1 & 1 & 0 & 1 & 1 & 9 \\
3 & 1 & 0 & 1 & 1 & 1 & 1 & 1 & 1 & 0 & 1 & 8 \\
4 & 1 & 1 & 1 & 1 & 1 & 1 & 1 & 1 & 0 & 1 & 9 \\
$\ldots$ & 0 & 0 & 0 & 0 & 1 & 1 & 1 & 1 & 1 & 0 & 5 \\
$\ldots$ & $\ldots$ & $\ldots$ & $\ldots$ & $\ldots$ & $\ldots$ & $\ldots$ & $\ldots$ & $\ldots$ & $\ldots$ & $\ldots$ & 10 \\
\hline \hline
\end{tabular}

Dari data responden di Tabel 3, maka dibentuk rangkuman referensi dengan cara mengurutkan kalimat berdasarkan nilai total pilihan secara descending, lalu diambil $12,5 \%$ kalimat dari jumlah kalimat total di artikel asli.

\section{Pembahasan}

Di penelitian ini digunakan ROUGE untuk mendapatkan nilai recall, yaitu nilai perbandingan rangkuman dari hasil otomasi dengan rangkuman referensi. Nilai recall di sini menunjukkan nilai relevansi hasil rangkuman sistem terhadap teks asli, sehingga semakin tinggi nilai ROUGE, semakin relevan hasil rangkuman yang diproduksi. Nilai rata rata recall ROUGE dari sistem automatic text summarization di atas yaitu 0,416594005 . Nilai persen dari rata-rata tersebut adalah $41,6594005 \%$. Nilai tertinggi recall ROUGE tertinggi tercatat pada artikel 48 dengan nilai 0,764705882 . Nilai terendah recall ROUGE tercatat pada artikel 37 dengan nilai 0,166666667 .

Dari percobaan tersebut diketahui bahwa perbandingan jumlah kata dan kalimat hasil sistem dengan hasil referensi memiliki perbedaan yang tidak terlalu jauh. Hal ini diketahui dengan nilai rata-rata kata \& kalimat yang dihasilkan dari kedua cara tersebut. Artikel asli memiliki rata-rata 812,68 kata dan rata-rata 49,76 kalimat. Rangkuman sistem memiliki rata-rata 132,92 kata dan 5,72 kalimat, sedangkan rangkuman referensi memiliki nilai rata-rata 122,6 kata dan 6,02 kalimat. Perbandingan nilai rata-rata tersebut ditunjukkan pada Tabel 4

Tabel 4. Perbandingan rata-rata jumlah kata dan kalimat.

\begin{tabular}{|c|c|c|c|c|c|c|}
\hline & $\begin{array}{l}\text { Isi Asli } \\
\text { (a) }\end{array}$ & $\begin{array}{c}\text { Rangkum } \\
\text { sistem } \\
\text { (rs) }\end{array}$ & $\begin{array}{c}\text { Rangkum } \\
\text { referensi } \\
\text { (rf) }\end{array}$ & rs : a (x) & rf : a (y) & Selisih $(x-y)$ \\
\hline Kata & 812,68 & 132,92 & 122,6 & 0,163557612 & 0,150858887 & 0,012698725 \\
\hline Kalimat & 49,76 & 5,72 & 6,02 & 0,114951768 & 0,120980707 & 0,006028939 \\
\hline
\end{tabular}

Dari tabel perbandingan di atas, diketahui bahwa hasil rangkuman sistem tidak berbeda jauh dengan rangkuman referensi dari segi kuantitas. Selisih perbandingan rata-rata kata rangkuman sistem dengan rangkuman referensi yaitu 0,012698725 dan selisih perbandingan rata-rata kalimatnya yaitu 0,006028939 .

Nilai ROUGE berbanding lurus dengan jumlah rangkuman yang dihasilkan. Hal ini diketahui dari perbandingan hasil rangkuman 50\% dan $12,5 \%$ dan evaluasi ROUGE tiap rangkuman. Perbandingan rata-rata antara rangkuman $50 \%$ dan $12,5 \%$ ditunjukkan pada tabel 5 .

Tabel 5. Perbandingan rata-rata rangkuman 50\% dan 12,5\%.

\begin{tabular}{|c|c|c|c|c|c|c|c|c|c|}
\hline \multirow{2}{*}{$\begin{array}{c}\text { Rangkum } \\
\text { an }\end{array}$} & \multicolumn{2}{|c|}{ Asli } & \multicolumn{2}{|c|}{$\begin{array}{l}\text { Rangkum } \\
\text { sistem }\end{array}$} & \multicolumn{2}{|c|}{$\begin{array}{l}\text { Rangkum } \\
\text { referensi }\end{array}$} & \multicolumn{2}{|c|}{ Jumlah Kata } & \multirow{2}{*}{$\begin{array}{c}\text { Nilai } \\
\text { ROUGE }\end{array}$} \\
\hline & Kata & $\begin{array}{c}\text { Kalim } \\
\text { at }\end{array}$ & Kata & $\begin{array}{c}\text { Kalim } \\
\text { at }\end{array}$ & Kata & $\begin{array}{c}\text { Kalim } \\
\text { at }\end{array}$ & $\begin{array}{c}\text { Overlappi } \\
n g\end{array}$ & $\begin{array}{l}\text { Refere } \\
\text { nsi unik }\end{array}$ & \\
\hline $50 \%$ & $\begin{array}{c}812,6 \\
8\end{array}$ & 53,52 & $\begin{array}{c}478,6 \\
2\end{array}$ & 24,38 & $\begin{array}{c}447,4 \\
6\end{array}$ & 24,66 & 186,22 & 252,22 & $\begin{array}{c}0,7291421 \\
4\end{array}$ \\
\hline $12,5 \%$ & $\begin{array}{c}812,6 \\
8\end{array}$ & 49,76 & $\begin{array}{c}132,9 \\
2\end{array}$ & 5,72 & 122,6 & 6,02 & 37,96 & 91,32 & $\begin{array}{c}0,4165940 \\
05\end{array}$ \\
\hline
\end{tabular}

Dari hasil sistem yang telah dirancang dan diimplementasikan, pengguna dapat memperoleh rangkuman dari sistem dengan hanya mengisi data dan beberapa kali klik. Jika dibandingkan dengan cara manual, pembuatan rangkuman menggunakan sistem yang otomatis ini memiliki perbedaan yang sangat signifikan. Dari segi waktu, perangkuman manual dengan cara memilih kandidat kalimat terbaik memakan waktu lebih banyak dari perangkuman menggunakan sistem. Melakukan perangkuman otomatis juga menggunakan sumberdaya tenaga dan pikiran manusia yang relatif lebih sedikit.

\section{KESIMPULAN}

Dari hasil dan pembahasan, didapatkan kesimpulan bahwa nilai relevansi hasil rangkuman penggunaan algoritma Textrank, jika dinilai dengan ROUGE adalah 41,659\%. Nilai tertinggi recall ROUGE tertinggi tercatat pada artikel 48 dengan nilai 0,764 . Nilai terendah recall ROUGE tercatat pada artikel 37 dengan nilai 0,167. Dari hasil sistem yang telah dirancang dan diimplementasikan, pengguna dapat memperoleh 
rangkuman dari sistem dengan waktu yang lebih sedikit karena melibatkan proses perhitungan komputer jika dibandingkan dengan merangkum secara manual.

\section{REFERENSI}

[1] Barzilay, R., Elhadad, M. 1997. Using Lexical Chains for Text Summarization. Mathematics and Computer Science Dept. Ben Gurion University in the Negev Beer-Sheva, Israel.

[2] Brin, S. Page, L. 1998. The Anatomy of a Large-Scale Hypertextual Web Search Engine. Stanford : Stanford University.

[3] Chengcheng, L. 2010. Automatic Text Summarization Based On Rhetorical Structure Theory. ICCASM 2010. Inner Mongolia Normal University, China.

[4] El Bazzi, M.S., Mammass, D., Zaki, T. 2016. A graph based method for Arabic documen indexing.Ibn Zohr University, Agadir, Maroko.

[5] Eris, E. Christanti, V. M. Pragantha, Jeanny. 2017. Penerapan Algoritma Textrank Untuk Automatic Summarization Pada Dokumen Berbahasa Indonesia. Universitas Tarumanegara, Jakarta.

[6] Kaynar, O. Isik, Y.E.,Gormez, Y. 2017.Graph Based Automatic Document Summarization with Different Similarity Methods. Cumhuriyet Universitesi, Sivas, Turki.1

[7] Kurniawan, A. Solihin, F., dan Hastarita, F. 2014. Perancangan dan Pembuatan Aplikasi Pencarian Informasi Beasiswa dengan Menggunakan Cosine Similarity. Jurnal SimanteC Volume 4, Nomor 2.

[8] Lin, C.Y. ROUGE : A Package for Automatic Evaluation of Summaries. 2004. California: Information Sciences Institute University of Southern California.
[9] Lutfi Firdaus Munawar, Lc. MA.. 2016. Tafsir Surat Al Insyirah di http://manhajuna.com/tafsir-surat-al-insyirah/ (diakses 8 Oktober 2019)

[10] Mani, I., Maybury, M.T.1999. Advances in Automatic Text Summarization. MIT Press.

[11] Mihalcea, R. Tarau, P. 2004. TextRank: Bringing Order into Texts. Texas : University of North Texas.

[12] Nanos, A.G., James, A.E., Iqbal. R., Hedley, Y.L. 2017. Content Summarisation of Conversation in the Context of Virtual Meetings: An Enhanced TextRank Approach. Distributed Systems Research Group, Coventry University, Coventry, United Kingdom

[13] Nurdiana, O., Jumadi., dan Nursantika, D. 2016. Perbandingan Metode Cosine Similarity dengan Metode Jaccard Similarity pada Aplikasi Pencarian Terjemahan Al-Qur'an dalam Bahasa Indonesia. Jurnal Online Informatika Volume 1,Nomor 1.

[14] Sabuna, P. M., Setyohadi, D.B.. 2017. Summarizing Indonesian Text Automatically By Using Sentence Scoring And Decision Tree. 2nd International Conferences on Information Technology, Information Systems and Electrical Engineering (ICITISEE). Universitas Atma Jaya Yogyakarta.

[15] Saggion,H .Poibeau, T. 2012. Automatic Text Summarization : Past, Present and Future .

[16] Zadbuke, A. Pimenta, S. Padwal, D. Wangikar, V. 2016. Automatic Summarization of News Articles using TextRank. IJARCSSE. University of Mumbai, Maharasshtra, India.

[17] Zhiqiang, L., Werimin, S., Zhenhua, Y. 2009. Measuring Semantic Similarity between Words Using Wikipedia. IEEE. 251-255.3 